\title{
Internal Audit Effectiveness: Data Screening and Preliminary Analysis
}

\author{
Mu'azu Saidu Badara ${ }^{1} \&$ Siti Zabedah Saidin ${ }^{1}$ \\ ${ }^{1}$ School of Accountancy, Universiti Utara Malaysia, Malaysia \\ Correspondence: Mu'azu Saidu Badara, School of Accountancy, Universiti Utara Malaysia, Malaysia. E-mail: \\ muazubadara@yahoo.com
}

Received: January 15, 2014 Accepted: April 17, 2014 Online Published: April 29, 2014

doi:10.5539/ass.v10n10p76

URL: http://dx.doi.org/10.5539/ass.v10n10p76

\begin{abstract}
The objective of this paper is to present internal audit effectiveness; data screening processes. Five hundred questionnaires were distributed to the respondents in various local governments in Nigeria through research assistance employed via stratified random sampling technique. Data were keyed into Statistical Package for Social Science (SPSS) version 21. Screening and cleaning of data was performed in order to suit the assumptions of multivariate analysis. Hence, response rate were ascertained, descriptive statistic, the assessment of missing data, univariate assessment and treatment of outliers, normality and multicollinearity were conducted. Similarly, Exploratory Factor Analysis (EFA) was also carried out via Principal Component Analysis (PCA). The result of the analysis revealed the significant and the suitability of the data for multivariate analysis.
\end{abstract}

Keywords: internal audit effectiveness, antecedents, local government, data screening, Nigeria

\section{Introduction}

In any multivariate analysis, one of the essentials aspect that is require due consideration is the issue concerning the analysis of data screening. Even Pallant (2001) expressed that, before starting any analysis of data, it is essential to check the data set for error because it is very easy to make mistake in data entry. In the same vein, data screening has significant positive effect over the meaningful and quality of any analysis result. Researchers concerned on such process are very minimal, perhaps due to long weight attached to such process (Hair, Black, Babin, \& Anderson, 2010). Even though, ignoring such process can definitely affect the predictive power of any analysis outcome, that is why is even noted that, in order to achieve consistency and accuracy in any analysis, data screening is one of the essential factor to be given due consideration (Tabachnick \& Fidell, 2007). This revealed the significant effects of data screening exercise on any variables analysis so that to enable the achievement of good outcome of such analysis.

Screening data that is very large is quite difficult (Pallant, 2001). But then, such screening need to be carry out so that even the hidden error that could not be seen can be easily traceable using any appropriate software such as Statistical Packages of Social Science (SPSS) any version (Hair et al., 2010). In addition, carrying out data screening could enable the researcher to comprehend the research variables interrelationship which thereafter enables good result interpretation. Similarly, such data screening could enable satisfying multivariate assumptions of data analysis which to some extent is more complicated to that of univariate data analysis. Based on these, the objective of this paper is to explore data screening process employed in ascertaining the antecedents of internal audit effectiveness. Section two discusses the literature review, section three is the methodology, result and discussion was presented in chapter four and finally the conclusion.

\section{Literature Review}

Internal audit effectiveness is necessary due to the fact that it bring perfection in the government organizational activities (Unegbu \& Kida, 2011). An operation can be regarded as effective if it produce result that is consistent with the established objective (Ussahawanitchakit \& Intakhan, 2011; Ahmad, Othman, \& Jusoff, 2009). Institute of Internal Audit (2010) defined internal audit effectiveness "as the degree to which established objectives are achieved. Pungas (2003) noted that, the objective of internal audit need to be clearly stated by the management of any organizations. Despite the fact that, the degree level of such effectiveness of internal audit tends to differ amongst various organizational operation as well as countries concerned (Al-Twaijry, Brierley, \& Gwilliam, 2003). Therefore, more research should be conducted on internal audit effectiveness, as even noted that only limited studies conducted on internal audit effectiveness all over the world (Endaya \& Hanefah, 2013). 
Effective internal control system entails the effective control measures established to enable the objective achievement of an organization; Glance (2006) defined internal control system as "the procedures and processes which local government council's put in place with the intention of achieving it established objective effectively". Internal control system is the procedures that help organizations in accomplishing its established goals (Vijayakumar \& Nagaraja, 2012; Jokipii 2010). In addition, Salawu and Agbeja (2007) posited that the credibility of internal auditor depends upon the internal control system effectiveness of an organization. That is why all government organizations are calling to enhance the effectiveness of their internal audit function, organization commitment and internal control system due to the fact they have positive significant effect on good governance (Eko \& Hariyanto, 2011). Even Badara and Saidin (2012) recommended the validation of effective internal control system relationship with internal audit effectiveness in different countries using different tools of analysis.

Risk management has been envisaged as an important schedule in private and public sectors recently (Wood, 2009; Anuntaakalakul, 2010). Due to the fact that, organizations that are exposed to the great extent of risk, is possible for them to fail in the attainment of their established objective respectively (Sumritsakun \& Ussahawanitchakit, 2009). In this vein, risk management need to be given due consideration, due to the fact that, effective risk management helps in the organizational objective achievement effectively (Gordon, Loeb, \& Tseng, 2009). Risk management deals with the identification of any kind of risks that is connected to organizational events and establishment of means that might responds to such risk. This involves putting into practice all the necessary controls which may enable the reducing of the possibility of happenings or the consequences of the risk (Vasile, Croitoru, \& Mitran, 2012). The relevant of the risk management process outcome can lead to the effectiveness of internal audit planning (Coetzee \& Fourie, 2009). That is why Badara and Saidin (2012) recommended for the empirical validation of such relationship between risk management with that of internal audit effectiveness using different tools of analysis.

Audit experience means, different kind of knowledge and skills which the auditors obtain due to length of tenure of the job practice in the auditing professions. Research in the field of professional experience in auditing and accounting are increasing recently (Badara \& Saidin, 2013; Gaballa \& Ning, 2011). Auditors are highly needed to utilize their auditing experience so that to achieve effectiveness in their auditing activities (Intakhan \& Ussahawanitchakit, 2010). Due to the fact that auditors that have more experience have a good comprehension of decision process and placed greater reliance on the net income variable (Messier, 1983). Auditors that have experience tend to conduct best audit practices so that to achieve better audit outcomes that would lead to audit success (Ussahawanitchakit, 2012). That is why even Badara and Saidin (2013) recommended the validation in future research on the audit experience relationship with internal audit effectiveness.

Cooperation between internal and external auditors refers to the coming together between the two auditors for the purpose of accomplishing certain common objectives. Study in cooperation between the two al auditors are increasing recently (Mihret \& Admassu, 2011; Fowzia, 2010). Effective cooperation amongst internal and external auditors leads to a greater quality of auditing exercise (Munro \& Stewart, 2011). In this vein, the cooperation should be given due consideration when it come to the effectiveness of internal audit issue. Such cooperation relationship between the two auditors has some advantages that include; better understanding by the external auditor of the organizational operations and improved client-relationship, fee reduction. Similarly, department of internal audit can equally take advantage of the external auditors knowledge in terms of other auditing procedures (Fowzia, 2010). In addition, such cooperation between internal and external audits enables the effectiveness of audits (Schneider, 2009).

Performance measurements in the aspect of internal audit are absolutely a vital theme for various experts (Ziegenfuss, 2000). Performance measurement in internal auditing has been given due consideration recently. This was due to the fact that internal audit constitutes one of the most essential managerial tasks (Rupsys \& Boguslauskas, 2007). In this vein, consideration must have to be given in the performance measurement of internal audit activities in various organization so that to enhance the effectiveness of internal audit. A standard performance measurement system could be employed in determining effective organizations strategic goals respectively (Kaplan \& Norton, 1996). Performance measurement refers to the process of determining the extent level of achievement of establish objective by internal auditors. It is very importance to consider performance measurement of internal auditor's activities in order to determine their level of effectiveness (Feizizadeh, 2012). Amirkhanyan (2011) realized that some performance measures are more effective than others. This indicated that performance measurement varies even in term of effectiveness. But then, performance measurement is still an important factor for maintaining effective and high quality of internal audit department (Ziegenfuss, 2000). This is because performance measurement was more supported towards efficiency and effectiveness of internal audit 
function (Rupsys \& Boguslauskas, 2007).

\section{Methodology}

Data for this study were obtained through a survey questionnaires administered to the internal auditors, audit committee and chairman or their representative of various local governments in Nigeria. The population of the study is the entire local government in Nigeria. There are 774 local government in Nigeria, based on this population, the sample size was 264 (Watson, 2001). To reduce the sample error in order to take care with non-response problem, the sample size has been increase to 500 (Hair et al., 2010). It is also recommended that the larger the sample size, the better (Pallant, 2001). The sampling technique was stratified random sampling, in which the populations were divided into stratum i.e., geo-political zones. This sampling technique it is an efficient research sampling technique because it provides more information on a given sample size (Sekaran \& Bougie, 2009). The data were administered and collected through research assistant employed so that to facilitate quick retrieval of completed research questionnaire and equally to provide high responds rate. After the retrieval of the data, the data were keyed in SPSS version 21.0 for further analysis.

\section{Results and Discussion}

Out of the 500 questionnaire distributed to the respondents, 365 were fully returned which lead to the achievement of high response rate of $73 \%$. Equally, out of the 365 questionnaires collected from the respondents, fifteen (15) questionnaires ware fund incorrectly completed and therefore, rejected for the purpose of analysis. This makes the remaining of 350 responses which represent the valid response rate of $70 \%$. A response rate of $30 \%$ is acceptable for survey (Hair et al., 2010). As been displayed in Table 1.

Table 1. Response rate of the questionnaires

\begin{tabular}{|c|c|c|c|c|c|c|c|c|}
\hline Responses & Bauchi & Kano & Niger & Lagos & Enugu & Cross- & SFCT & Total/Rate \\
\hline No. of distributed questionnaire & 67 & 146 & 83 & 67 & 57 & 60 & 20 & 500 \\
\hline Returned questionnaires & 67 & 115 & 60 & 42 & 40 & 21 & 20 & 365 \\
\hline Returned and usable questionnaires & 65 & 110 & 57 & 40 & 37 & 21 & 20 & 350 \\
\hline Returned and excluded questionnaires & 2 & 5 & 3 & 2 & 3 & 0 & 0 & 15 \\
\hline Questionnaire not returned & 0 & 31 & 23 & 25 & 17 & 39 & 0 & 135 \\
\hline Response rate & $100 \%$ & $78.7 \%$ & $72.2 \%$ & $62.6 \%$ & $70.1 \%$ & $35 \%$ & $100 \%$ & $73 \%$ \\
\hline Usable response rate & $97 \%$ & $75 \%$ & $69 \%$ & $60 \%$ & $65 \%$ & $35 \%$ & $100 \%$ & $70 \%$ \\
\hline
\end{tabular}

The descriptive analysis of the study revealed that $74.6 \%$ of the respondents were male while $25.4 \%$ of the respondents were female; this shows that must of the internal auditors, audit committee members as well as the chairman or their representative of the various local government in the study were male, only few were female. Also descriptive statistical analysis showed that, respondents between the ages of 30-35 years old were $27.4 \%$ which is the highest, followed by the respondents at the age of 35-40 years old which has the percentage of $23.1 \%$. The age between $25-30$ years old and $40-45$ years old has equal percentages of $18.9 \%$; this is followed by the age above 45 years old that has $9.4 \%$ and finally $2.3 \%$ which has less than 25 years old. This revealed that the majority of the respondents are still within the productive groups of the entire population which to some extent their responses can equally be fair.

For educational background of the respondents, descriptive statistic revealed that $47.4 \%$ the respondents has Diploma certificate/National Certificate on Education (NCE). This is followed by those that have degree certificate/Higher National Diploma (HND) with the percentage of 34.3\%. Similarly, those that have certificates are within $8.3 \%$, which is followed by those that have Masters Qualification with $6 \%$ and finally the respondents that have only secondary school certificate with $4 \%$. The academic background of the respondents is quite interesting despite the fact that they are from local government, as you can see some of the respondents has degree certificates while some has Master's Degree qualification which is very fabulous at local level, even though the majority of the respondents are within the education level of Diploma certificate/National Certificate on Education (NCE). To this end, the academic qualification of the respondents is quite impressing.

With regard to professional qualification of the respondents, descriptive statistic revealed that majority of the respondents do not have professional qualification with the highest percentage of $78.9 \%$ and this is in line with the above educational background that most of the respondents are within the educational level of Diploma certificate/National Certificate on Education (NCE), and therefore, is not possible to get professional certificate 
at that levels of education unless you have degree certificate in the related field. This is followed by those that have certificates membership of one of the professional accounting body which is Association of National Accountant of Nigeria (ANAN) with 13.4\%. Similarly, those that have the professional certificate of the membership of Institute of Certified Public Accountant of Nigeria (ICPAN) are within the percentage of 6\% while only $1.4 \%$ of the respondents have professional certificate of the membership of Institute of Charted Accountant of Nigeria (ICAN) and finally, $0.3 \%$ of the respondent has others specify which is professional membership certificate of the Nigerian Institute of Management (NIM). This indicates that the respondents to some extent are professionally qualified.

With respect to working experience, descriptive statistical analysis showed that $32 \%$ of the respondents have working experience from 15 years-Above, this is followed by the respondents that have working experience of 6-10 years which is $25.1 \%$. Similarly, $21.7 \%$ of the respondents have the working experience of $1-5$ years, while $19.7 \%$ of the respondents have the working experience of the range of $11-15$ years and finally, $1.4 \%$ of the respondents have the working experience that is less than 1 year. Therefore, it could be said that the respondents have sufficient working experience with their respective local government to respond to the research questions, as can be seen in Table 2 .

Table 2. Background information of the respondents

\begin{tabular}{|c|c|c|c|}
\hline Demographic profile & Categories & Frequency & $\%$ \\
\hline \multirow{3}{*}{ Gender } & Male & 261 & 74.6 \\
\hline & Female & 89 & 25.4 \\
\hline & Total & 350 & 100.0 \\
\hline \multirow{8}{*}{ Age } & Less than 25 years old & 8 & 2.3 \\
\hline & 25 years- 30 years old & 66 & 18.9 \\
\hline & 30 years- 35 years old & 96 & 27.4 \\
\hline & 35 years -40 years old & 81 & 23.1 \\
\hline & 40 years -45 years old & 66 & 18.9 \\
\hline & Above 45 years old & 33 & 9.4 \\
\hline & Total & 350 & 100.0 \\
\hline & Secondary certificate & 14 & 4.0 \\
\hline \multirow{5}{*}{ Highest school qualification } & Certificate & 29 & 8.3 \\
\hline & Diploma/NCE & 166 & 47.4 \\
\hline & Degree/HND & 120 & 34.3 \\
\hline & Masters & 21 & 6.0 \\
\hline & Total & 350 & 100.0 \\
\hline \multirow{6}{*}{ Professional qualification } & ICAN member & 5 & 1.4 \\
\hline & ANAN member & 47 & 13.4 \\
\hline & ICPAN member & 21 & 6.0 \\
\hline & None & 276 & 78.9 \\
\hline & Others specify & 1 & .3 \\
\hline & Total & 350 & 100.0 \\
\hline \multirow{6}{*}{ Working experience } & Less than 1 year & 5 & 1.4 \\
\hline & $1-5$ years & 76 & 21.7 \\
\hline & $6-10$ years & 88 & 25.1 \\
\hline & $11-15$ years & 69 & 19.7 \\
\hline & 15 years-Above & 112 & 32.0 \\
\hline & Total & 350 & 100.0 \\
\hline
\end{tabular}

\subsection{Missing Data}

Looking at the negative effect of missing data in any analysis, the researcher takes an action toward reducing it. At the receiving of the completed questionnaire, the research assistants employed checked and ensured that all questions were answered. In some cases were the respondents forget to fill some question, he/she was kindly requested to complete the questionnaire appropriately. Hence, this perhaps play a significant role toward reducing the rate of missing data for the survey. After the data were collected, they were entered into SPSS 
software and therefore, preliminary descriptive statistic was run with aim to discover whether or not missing data exist. The result revealed that there is no missing data.

\subsection{Assessment of Outliers}

Assessment and treatment of outliers is another essentials aspect of screening data. It is the extreme cases scores that might have a significant negative effect on the analysis outcome, it can be very high, it can equally be very low or special mixture of values across several variables, and this has to be deleted (Hair et al., 2010). They are case scores that are extreme and therefore have a much higher impact on the outcome of any statistical analysis and are usually cause by mistake in data entry, missing values and the population of the study (Froh, 2007). Therefore, multivariate analysis necessitates the identification and treatment of outliers accordingly. Even though there are different approaches to detect and treat outliers. In this respect, univariate outliers were checked. Univariate outliers ware checked using SPSS by detecting cases with large z-score values. Therefore, any cases with standardized z-sore value greater than 3 ware eliminated. Hence, 41 cases from this study ware been deleted for further analysis, and this made the remaining items to be 309 from the initial 350 .

\subsection{Normality Test}

Normality is the most essential assumption in multivariate analysis (Hair et al., 2010). It refers to distribution of data to particular variable and its corresponding to normal distribution. This means the data needs to follow a normal distribution in order to allowed analyses to work properly and make a stronger assessment (Froh, 2007). Pallant (2001) and Hair et al., (2010) suggested that, in order to meet up with the underlying assumption of a multiple regression analysis, normality of the data need to be checked. Normality screening is an essential step in almost all multivariate analysis (Tabachnick \& Fidell, 2007). There are two main ways for assessing normality: graphically and numerically. The graphical used: histogram and boxplot normal quartile plot which is also called Normal probability plot). While the numeric used: Kolmogorov-Smirnov Test.

This study used histogram (because its provide data representation graphically) to demonstrate the normality of the distribution. Similarly, Tanbakuchi (2009) provide two rules on assessing the normality using histogram i.e. (a) Make a histogram: the normality should be rejected if dramatically departs from bell shape R: hist (x) and (b) Make a normal quartile plot: Reject if plot does not closely follow a line. R: qqnorm (x); qqline (x). Figure 1 depicted the histogram of the variable which indicated that the normality assumption has been achieved because the histogram gave a bell shape 'normal curve' therefore, is accepted going by the rule of (Tanbakuchi, 2009).

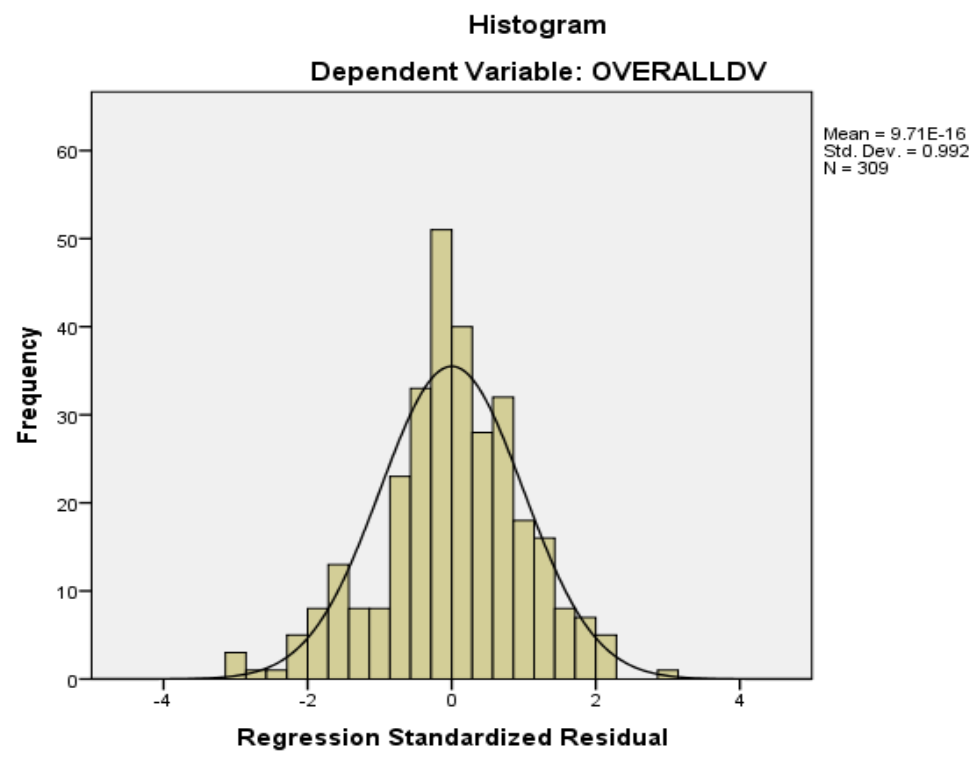

Figure 1. Histogram for normality distribution of the dependent variable: Internal audit effectiveness 


\subsection{Multicollinearity}

In an ideal situation, independent variables are supposed to be highly correlated with the dependent variables than with other independent variables. Nevertheless, multicollinearity occurs as a result of highly correlation of independent variables with one another or exists when one independent variable is at linear combination with other independent variables (Keith, 2006). Independent variables are highly correlated among themselves when they are at (0.9 or above) (Hair et al., 2010; Tabachnick \& Fidell, 2007). When independent variables are highly correlated with one another (multicollinearity) increase the standard errors of the variables coefficient and thereby makes some independent variables statistically not significant while they could be in other way significant. Hence, affect the predictive power of the model, thus, the present of the multicollinearity lead to the present of the standard errors. If multicollinearity cases are detected, it can be resolve by deleting the affected variables. Checking the multicollinearity problem can be done by bivariate correlation of all the independent variables.

In this regard, multicollinearity has been examined between the independent variables (antecedents) in this study using Pearson's correlation as to be shown in Table 3. A correlation analysis has been carried out in order to clarify the relationship among all the variables and Pearson's correlation was used to examine the correlation coefficient between the variables. Table 3 present the correlation for the variables. This was conducted before hypothesis testing with the aim of determining the extent to which the variables are related. The values of Pearson's exhibit the relationship between independent variables, this serve as a method for diagnosing multicollinearity (Allison, 1999) and equally Allison (1999) shows that any correlation that is 0.8 or higher is problematic.

Table 3. Pearson's correlation between variables

\begin{tabular}{lllllll}
\hline & IAE & EICS & RM & PM & AE & CBIE \\
\hline Internal Audit Effectiveness (IAE) & 1 & & & & & \\
Effective Internal Control System (EICS) & $.138^{*}$ & 1 & & & & \\
Risk Management (RM) & $.228^{* *}$ & $.281^{* *}$ & 1 & & & \\
Performance Measurement (PM) & $.196^{* *}$ & $.260^{* *}$ & $.289^{* *}$ & 1 & & \\
Audit Experience (AE) & $.343^{* *}$ & $.160^{* *}$ & $.292^{* *}$ & $.162^{* *}$ & 1 \\
Cooperation Btw Internal and External auditors (CBIE) & $.209^{* *}$ & $.299^{* *}$ & $.322^{* *}$ & $.184^{* *}$ & $.201^{* *}$ & 1 \\
\hline
\end{tabular}

**. Correlation is significant at the 0.01 level (2-tailed).

*. Correlation is significant at the 0.05 level (2-tailed).

The correlation analysis of the variables under study was subjected to a two-tailed test of statistical significance at two different level; significant $(\mathrm{p}<0.01)$ and significant $(\mathrm{p}<0.05)$, Table 3 above shows that correlations between all variables under study are statistically significant at $(\mathrm{p}<0.01)$ and $(\mathrm{p}<0.05)$. It can also be seen from the same table 3 that the correlation of the variables ranges from 0.138 to 0.343 . Hence, the problem of multicollinearity is not there.

Another way to verify the issue of multicollinearity is through the examination of Variance Inflation Factors (VIF) and tolerance values via regression result. The rule of thumb for a Variance Inflation Factors (VIF) larger value is ten (10), any VIF that is above 10 and smaller values is the aspect of tolerance is an indication of multicollinearity (Keith, 2006). Similarly, any VIF values that exceed 10 and tolerance values that is less than 0.10 indicates potential multicollinearity problem (Hair et al., 2010). Therefore, to avoid multicollinearity problem, the VIF values should not exceed 10 and the tolerance values should not be less than 0.10 . Thus, Table 4 exhibits the Tolerance and Variance Inflation Factors (VIF) values of the independent variables.

Table 4. Tolerance and VIF values for multicollinearity test

\begin{tabular}{lll}
\hline Independent Variables & $\begin{array}{l}\text { Collinearity Statistics } \\
\text { Tolerance }\end{array}$ & VIF \\
\hline Effective Internal Control System & .823 & 1.215 \\
Risk Management & .730 & 1.369 \\
Audit Experience & .730 & 1.370 \\
Cooperation between Internal and External Auditors & .813 & 1.231 \\
Performance Measurement & .801 & 1.249 \\
\hline
\end{tabular}


The above Table 4 indicates that multicollinearity does not occur among the independent variables because the tolerance values range between 0.73 and 0.82 which is greater than 0.10. Likewise, the Variance Inflation Factors (VIF) range from 1.22 to 1.37 which is less than 10, thus, is acceptable (Tabachnick \& Fidell, 2007). Hence, it is concluded that the independent variables under study does not have multicollinearity problem.

\subsection{EFA for Exogenous Variables}

At the inspection of the correlation matrix, the correlation matrix revealed the presence of many coefficients of 0.3 and above thereby, satisfying one of the first requirements for conducting (PCA). As there are no correlation matrix values that is 0.9 or above, thus, the data is free from issue of multicollinearity. The Kaiser-Meyer-Olkin value is 0.724 exceeding the recommended value of 0.5 , showing that the sample size is adequate for factor analysis to be conducted. Similarly, the Bartlett's test of Sphericity is statistical significant, supporting the factorability of the correlation matrix as the p-value is 0.000 , which implies the adequacy of applying the factor analysis. Principal Component Analysis (PCA) revealed the presence of five (6) components with eigenvalue exceeding 1, explaining $23.67 \%, 10.43 \%, 9.07 \%, 8.82 \%$, and $7.43 \%$ of the variance respectively. Using the decision of Raiche, Riopel, \& Blais (2013), it was decided to retain five (5) components for further investigation. To aid in the interpretation of these five (5) components, Varimax rotation was equally performed. The rotated solution displayed the presence of a simple structure (Thurstone, 1931) with all components showing a number of strong loadings. The five (5) factor solution explained a total of $59.41 \%$ of the variance, with component 1 contributing 23.67\%; component 2 contributing 10.43\%; component 3 contributing 9.07\%; component 4 contributing $8.82 \%$; and component 5 contributing $7.43 \%$ respectively. Table 5 below shows the factor loadings and communality values for each item.

Table 5. Factor loading and communality for exogenous variables

\begin{tabular}{lll}
\hline ITEMS & Loadings & Communality \\
\hline A1 & .782 & .680 \\
A2 & .852 & .762 \\
B4 & .678 & .657 \\
B5 & .821 & .759 \\
C1 & .802 & .683 \\
C5 & .750 & .632 \\
D3 & .798 & .688 \\
D4 & .793 & .670 \\
E1 & .857 & .771 \\
E2 & .819 & .732 \\
E3 & .675 & .652 \\
\hline
\end{tabular}

Extraction Method: Principal Component Analysis

\subsection{EFA for Endogenous Variables}

The Table 6 below displayed the outcome of factor analysis for the dependent variable (internal audit effectiveness). At the beginning, the dependent variable was measured by 9 items which was subjected to principal component analysis (PCA) using SPSS Version 21. Normally, before conducting PCA, the appropriateness of data for factor analysis was assessed. At the inspection of the correlation matrix, it was found the presence of many coefficients of 0.3 and above thereby, satisfying one of the first requirements for conducting (PCA). As there are no correlation matrix values that is 0.9 or above, thus, the data is free from issue of multicollinearity. The factor loading of the items ranged from 0.698 to 0.883 with 5 (five) items being removed for various reasons such as having low values in Measure of Sampling Adequacy (MSA), low communalities value, loading less than 0.50 and complex structure (cross-loading). Removing these items with low communalities values increased the total variance explained.

The result of Kaiser-Meyer-Olkin (KMO) measure the sampling adequacy is 0.591 exceeded the benchmark value of 0.50 , indicating that the sample size is adequate for factor analysis to be conducted. That is, the ratio of the sample size to the number of items is adequate for factorability. Similarly, the Bartlett's test of Sphericity was found significant statistically thereby supporting the factorability of the correlation matrix as the p-value is 0.000 . This implies the adequacy of applying the factor analysis. Principal component's analysis (PCA) displayed the presence of two components with eigenvalue exceeding 1. The two components extracted were named 1) (G7) 
and 2) (G3). The percentages of the variances were $43.89 \%$ and $26.41 \%$ respectively. The two components solution explained a total of $70.29 \%$ of the variance.

Table 6. Factor loading and communality for exogenous variables

\begin{tabular}{lll}
\hline ITEMS & Loadings & Communality \\
\hline G1 & .800 & .677 \\
G3 & .883 & .785 \\
G7 & .862 & .742 \\
G4 & .698 & .607 \\
\hline
\end{tabular}

Extraction Method: Principal Component Analysis

\section{Conclusions}

This paper present internal audit effectiveness data screening which involved different processes in order to achieve the aim of the research, the processes comprised; the presentation of the response rate of the respondents which is quite impressing because a high response rate of $70 \%$ has been achieved. Descriptive statistic of the respondent was then presented, the issue concerning missing data, assessment of outliers and treatment, normality and multicollinearity has also been discussed in the paper. Finally, the exploratory factor analysis of both independent and the dependent variables was equally revealed in the paper.

\section{References}

Ahmad, N., Othman, R., \& Jusoff, K. (2009). The effectiveness of internal audit in Malaysian public sector. Journal of Modern Accounting and Auditing, 5(9), 784-790.

Allison, P. (1999). Multiple regressions: A primer. CA; Pine Forge Press.

Al-Twaijry, A. A. M., Brierley, J. A., \& Gwilliam, D. R. (2003). The development of internal audit in Saudi Arabia: An Institutional Theory perspective. Critical Perspective on Accounting, 14, 507-531. http://dx.doi.org/10.1016/S1045-2354(02)00158-2

Amirkhanyan, A. A. (2011). What is the effect of performance measurement on perceived accountability effectiveness in State and Local Government contracts? Public Performance \& Management Review, 35(2), 303-339. http://dx.doi.org/10.2753/PMR1530-9576350204

Anuntaakalakul, A. (2010). The achievement in risk management and governance of public sector organizations in Thailand: The Empirical Evidence of Internal Auditing efforts. EABR \& ETLC Conference Proceedings Dublin, Ireland, 99-104.

Badara, M. S., \& Saidin, S. Z. (2012). Impact of the effective internal control system on the internal audit effectiveness at local government level. Journal of Social and Development Sciences, 4(1), 16-23.

Badara, M. S., \& Saidin, S. Z. (2012). The relationship between risk management and internal audit effectiveness at local government level. Journal of Social and Development Sciences, 3(12), 404-411.

Badara, M. S., \& Saidin, S. Z. (2013). The relationship between audit experience and internal audit effectiveness in the public sector organizations. International Journal of Academic Research in Accounting, Finance and Management Sciences, 3(3), 329-339.

Coetzee, P., \& Fourie, H. (2009). Perceptions on the role of the internal audit function in respect of risk. African Journal of Business Management, 3(13), 959-968.

Eko, S., \& Hariyanto, E. (2011). Relationship between internal control, internal audit, and Organization commitment with good governance: Indonesian Case. Retrieved from http://www.sawaedy.com/images/pdf/ic.pdf

Endaya, K. E., \& Hanefah, M. M. (2013). Internal audit effectiveness: An approach proposition to develop the theoretical framework. Research Journal of Finance and Accounting, 4(10), 92-102.

Feizizadeh, A. (2012). Strengthening internal audit effectiveness. Indian Journal of Science and Technology, 5(5), 2777-2778.

Fowzia, R. (2010). Co-operation between internal and external auditors: A comparative study on Nationalized and Foreign Banks in Bangladesh. World Journal of Management, 2(2), 22-35. 
Froh, J. J. (2007). Data Screening Check List. Retrieved December 9, 2013, from http://people.hofstra.edu/Jeffrey_J_Froh/files/Data\%20Screening\%20Check \%20List_J.Froh.1.29.08.pdf

Gaballa, A. S. M., \& Ning, Z. (2011). An analytical study of the effects of experience on the performance of the external auditor. International Conference on Business and Economics Research, 1, 169-173.

Glance, A. (2006). Effectiveness of internal control. Local Government: Results of the 2006-07 Audits, 19-26.

Gordon, L. A., Loeb, M. P., \& Tseng, C. (2009). Enterprise risk management and firm performance: A contingency perspective. $J$. Account. Public Policy, 28, 301-327. http://dx.doi.org/10.1016/j.jaccpubpol.2009.06.006

Hair, J., Black, W. C., Babin, B. J., \& Anderson, R. E. (2010). Multivariate analysis (7th ed.). Upper saddle River, New Jersey: Pearson Education International.

IIA. (2010). Measuring internal audit effectiveness and efficiency. IPPF-Practice guide. The Institute of Internal Auditors.

Intakhan, P., \& Ussahawanitchakit, P. (2010). Roles of audit experience and ethical reasoning in audit professionalism and audit effectiveness through a moderator of stakeholder pressure: An empirical study of tax auditors in Thailand. Journal of Academy of Business and Economics, 10(5), 1-15.

Jokipii, A. (2010). Determinants and consequences of internal control in firms: A contingency theory based analysis. J. Manag. Gov., 14, 115-144. http://dx.doi.org/10.1007/s10997-009-9085-x

Kaplan, R. S., \& Norton, D. P. (1996). Using balance scorecard as a strategic management system. Harvard Business Review, 75-85.

Keith, T. (2006). Multiple regressions and beyond. PEARSON Allyn \& Bacon.

Mihret, D. G., \& Admassu, M. A. (2011). Reliance of external auditors on internal audit work: A corporate governance perspective. International Business Research, 4(2), 67-79. http://dx.doi.org/10.5539/ibr.v4n2p67

Munroa, L., \& Stewart, J. (2011). External auditors' reliance on internal auditing: Further evidence. Managerial Auditing Journal, 26(6), 464-481. http://dx.doi.org/10.1108/02686901111142530

Pallant, J. (2001). SPSS survival manual. A step by step guide to data analysis using SPSS for windows (Version 10, 1st ed.). Allen \& Unwin Australia.

Pungas, K. (2003). Risk assessment as part of internal auditing in the government institutions of the Estonian Republic. EBS Review Summer, 42-46.

Raiche, G., Riopel, M., \& Blais, J. (2013). Non Graphical Solutions for the Cattell's Scree Test. Methodology, 9(1), 23-29.

Rupsys, R., \& Boguslauskas, V. (2007). Measuring performance of internal auditing: Empirical evidence. Engineering Economics, 5(55), 9-15.

Salawu, R. S., \& Agbeja, O. (2007). Auditing and accountability in the public sector. International Journal of Applied Economics and Finance, 1(1), 45-54.

Schneider, A. (2009). The nature, impact and facilitation of external auditor reliance on internal auditing. Academy of Accounting and Financial Studies Journal, 13(4), 41-53.

Sekaran, U., \& Bougie, R. (2009). Research method for business; a skill building approach (5th ed.). A john Wiley and sons, Ltd. United Kingdom.

Sumritsakun, C., \& Ussahawanitchakit, P. (2009). Internal audit innovation and firm stability of Thai listed company: How do implement in an organization? Journal of Academy of Business and Economics, 9(4), $1-23$.

Tabachnick, B. G., \& Fidell, L. S. (2007). Using multivariate statistic (5th ed.). Boston: Pearson Education Inc.

Tanbakuchi, A. (2009). Introductory Statistics Lectures: Assessing Normality. Department of Mathematics Pima Community College. Retrieved September 18, 2013, from http://www.tanbakuchi.com/Courses/MAT167/Files/LH_LEC.0450.RandVar s.AssesNorm.pdf

Unegbu, A. O., \& Kida, M. I. (2011). Effectiveness of internal audit as instrument of improving public Sector management. Journal of Emerging Trends in Economics and Management Sciences (JETEMS), 2(4), 304-309. 
Ussahawanitchakit, A., \& Intakhan, A. (2011). Audit professionalism, audit independence and audit effectiveness of CPAs in Thailand. International Journal of Business Research, 11(2), 1-11.

Ussahawanitchakit, P. (2012). Audit independence of tax auditors in Thailand: Roles of ethical orientation, professional responsibility, stakeholder pressure, and audit experience. Journal of Academy of Business and Economics, 12(1), 1-11.

Vasile, E., Croitoru, I., \& Mitran, D. (2012). Risk management in the financial and accounting activity. Internal auditing \& risk management Annul, 1(25), 13-24.

Vijayakumar, A. N., \& Nagaraja, N. (2012). Internal control systems: Effectiveness of internal audit in risk management at public sector enterprises. BVIMR Management Edge, 5(1), 1-8.

Watson, J. (2001). How to Determine a Sample Size: Tip sheet \#60, University Park. PA: Penn State Cooperative Extension. Retrieved October 21, 2012, from http://www.extension.psu.edu/evaluation/pdf/TS60.pdf

Woods, M. (2009). A contingency theory perspective on the risk management control system within Birmingham City Council. Management Accounting Research, 20, 69-81. http://dx.doi.org/10.1016/j.mar.2008.10.003

Ziegenfuss, D. E. (2000). Measuring performance. The Internal Auditor, 57(1), 36-40.

\section{Copyrights}

Copyright for this article is retained by the author(s), with first publication rights granted to the journal.

This is an open-access article distributed under the terms and conditions of the Creative Commons Attribution license (http://creativecommons.org/licenses/by/3.0/). 